\title{
İmplant Destekli Protetik Restorasyonlarda Kullanılan Ölçü Yöntemleri ve Materyalleri: Derleme
}

\author{
Impression Techniques and Materials Used in Implant Supported Prosthetic Restorations: A \\ Review
}

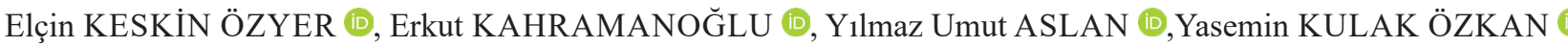

$\ddot{O} z$

Protetik diş tedavilerinde rehabilite edilecek bölgenin negatifini en doğru şekilde elde etmek, yapılacak olan restorasyonun başarısını doğrudan etkilemektedir. Kullanılan ölçü maddesi, kaşık seçimi ve ölçü tekniğinde yapılan hatalar; kuvvet dağılımında eşitsizlik, protez ve abutment vidası gevşemesi ve okluzal düzensizlikler gibi protetik komplikasyonlara neden olmaktadır. Başarılı bir restorasyon için implantların pozisyonlarının ve birbiriyle ilişkilerinin ana modele birebir transfer edilmesi ve ölçüde hassasiyetin sağlanması gerekmektedir.

Diş destekli protezlerle implant üstü protezler karşılaştırıldığında, dental implantların periodonsiyum içermemesi ve ortodontik hareket yapma yeteneğinin bulunmaması ölçüde meydana gelecek uyum hatalarının tolere edilmesini kısıtlamaktadır. Bu nedenle implant üstü protetik restorasyonların ölçü işleminde çok daha fazla teknik hassasiyete ihtiyaç duyulmaktadır.

$\mathrm{Bu}$ derleme geçmişten günümüze kullanılan ölçü maddelerinden bahsederek, implant üstü protetik restorasyonlarda kullanılan ölçü tekniklerini ve ölçü alımındaki yenilikleri geniş bir yelpazede incelemek amacı ile yazılmıştır.

Anahtar Kelimeler: Ölçü teknikleri, ölçü materyalleri, implant destekli protezler.

Elçin KESKIN ÖZYER (四)

Doktora Öğrencisi, Marmara Üniversitesi Diş Hekimliği Fakültesi, Protetik Diş Tedavisi Anabilim Dalı İstanbul, Türkiye

Tel: 0216.412.1621, Fax: 021.642.10291

elcinozyer@marun.edu.tr

Erkut KAHRAMANOĞLU, Yılmaz Umut ASLAN

Doktor Öğretim Üyesi, Marmara Üniversitesi Diş Hekimliği Fakültesi,

Protetik Diş Tedavisi Anabilim Dalı İstanbul, Türkiye

Yasemin KULAK ÖZKAN

Profesör Doktor, Marmara Üniversitesi Diş Hekimliği Fakültesi, Protetik Diş Tedavisi Anabilim Dalı Istanbul, Türkiye

Submitted / Gönderilme: 21.03.2019 Accepted / Kabul: 25.06.2019

\begin{abstract}
In prosthodontics; acquiring the negative of the region to be rehabilitated in the most accurate way, directly affects the success of the restoration. The faults in choosing the impression material, tray selection and technique; may cause inequality in force distribution, prosthetic and abutment screw loosening and occlusal irregularities. For a successful restoration, the intraoral positions of the implants and their interrelationships must be exactly transferred to the main model and the precision of implant impression must be ensured.

Compared to denture - supported prostheses and implant based protheses, dental implants do not have periodontium and the ability to make orthodontic movements, restricts the ability to tolerate errors. Therefore more technical precision is needed in the measurement of implant supported prosthetic restorations.

In this review; the impression techniques used in implant supported prosthetic restorations were described and in a wide range the innovations in taking impression were evaluated.
\end{abstract}

Keywords: Impression technique, impression material, implant supported prosthetic restorations.

\section{GİRIŞ}

Dental implantlar günümüzde tartışmasız olarak doğal dişlere en iyi alternatiftir. Konvansiyonel protezlerde destek; dişlerden, kemikten ve çevre yumuşak dokulardan sağlanmaktadır. İmplant üstü protetik tedavide ise, implantların destek olarak alınması ile birlikte kemik dokusu rezorbsiyonunun önüne geçilmiş, çiğneme etkinliği ve hastanın yeni duruma adaptasyonu ve hasta memnuniyeti arttırılmış olmaktadır (Naert ve ark., 1991).

İmplant destekli protetik restorasyon için tedavi planlaması çok önemlidir. İmplant destekli protezlerin planlanmasında gerek değişen kemik özellikleri gerekse dişlerle olan ilişkisine göre farklı tedavi yöntemleri vardır ve tedavilerde başarıya ulaşabilmek için hem cerrahi hem de protetik açıdan doğru ve eksiksiz bir endikasyon ve hatasız uygulama gerekmektedir (Kahramanoğlu ve Özkan, 2013). 
İmplant destekli protezlerin endikasyonları aşağıdaki gibi stralanabilir:

1. Total dişsizlik vakaları
a.) İmplant destekli sabit protezler
b.) İmplant destekli hareketli protezler

2. Kısmi dişsizlik vakaları
a.) Tek diş eksiklikleri
b.) Serbest sonlanan bölgeler
c.) Ara dişsiz boşluklar (Branemark, 1985).

İmplant destekli protetik restorasyonlarda başarılı bir tedavinin en önemli faktörü pasif uyumlu protetik restorasyonlardır (Şahin ve ark, 2002). Restorasyonun uyumu, protetik sistemde ya da çevre dokuda statik bir yük oluşturmuyorsa pasif uyum olarak adlandırılır. Restorasyonun pasif uyumlu olabilmesi için ölçünün doğru alınması, tekniğinin doğru seçilmesi ve uygun ölçü maddesinin kullanılması çok önemlidir. Hatalı bir ölçü sonucunda oluşabilecek implant komponentleri ve protez arasındaki uyumsuzluk; vida gevşemesi, vida kırığı, plak birikiminde artış, osseointegrasyon kaybı ve hatta implant kırı̆ğ gibi hem mekanik hem de biyolojik komplikasyonlara neden olabilmektedir.

\section{2. ÖLÇÜ TEKNIKLLERİ}

Geleneksel ve dijital ölçü yöntemleri olmak üzere 2 ana başlı̆ga ayrılmaktadır (Carr, 1992).

\subsection{Geleneksel Ölçü Yöntemleri}

Kapalı Kașık Metodu / İndirekt Teknik / Transfer Yöntemi

Ölçü başlıklarının implantlar üzerine yerleştirilmesi sonrasında, hazır kaşık ile ölçü alınması söz konusudur.

\section{Indirekt ölçü alımında aşamalar,}

- Osseointegre olmuş implantın iyileşme başlığı çıkartılır.

- Ölçü başlıkları ağız içerisinde implantlar üzerine yerleştirilir.

- Hazır kaşık ve uygun ölçü materyali ile ölçü alınır.

- Ölçü materyalinin sertleştiğinden emin olduktan sonra, hasta ağzından çıkartılır.
- Ölçü transfer başlığı, hasta ağzından çıkartılarak, laboratuvar aşaması için uygun analoğuna yerleştirildikten sonra, tekrar ölçü içerisine yerleştirilir.

Avantajlarl,

- Direkt metoda nazaran, klinik uygulamada hekime kolaylık sağlayan ve bu nedenle klinikte hekimler tarafından daha çok tercih edilen bir metottur.

- Direkt metot uygulanırken ölçü başlıklarının gevşetilmesi esnasında rotasyonel bir hareket olasıllı̆̆ söz konusuyken, indirekt teknikte ise bu durum söz konusu olmaz. Böylelikle bu rotasyonel hareket nedeniyle oluşabilecek bir distorsiyon önlenmiş olur (Carr, 1992).

- Ölçü başlığı ve implant analoğunun elde birleştirilmesinin daha güvenilir olması bu tekniğin avantajlarındandır.

Dezavantajlarl,

- Ölçü içerisine ölçübaşlıklarının tekraryerleştirilmesi esnasında hata oluşması kaçınılmazdır.

- Ölçü materyalinin, hazır kaşık kullanımı nedeniyle her yerde eşit dağılım ve eşit kalınlık sergilememesinin implant ölçüsünde hatalara neden olduğu belirtilmiştir.

- İmplantların paralel olarak yerleştirilmediği durumlarda indirekt yöntem kullanıldığında, kaşığın ağızdan uzaklaştırılması sırasında ölçü başlıkları ölçü materyalinde deformasyona neden olabileceği bildirilmiştir (Choi ve ark., 2007).

Açık Kașık Metodu / Direkt Teknik / Pick-up Ölçü Yöntemi

Ölçü analoglarının implantlar üzerine yerleştirilmesi sonrasında, başlıkların denk geldiği yerlerde hazırlanan deliklerin mevcut olduğu özel kaşık ile ölçü alınır.

Direkt ölçü alımında aşamalar;

- Osseointegre olmuş implantın iyileşme başlığ1 çıkartılır.

- Aljinat ya da benzer ölçü maddeleri kullanarak standart ölçü kaşığı ile ölçü alınarak elde edilen birinci modelde yumuşak dokunun olduğu rezidüel kretin yumuşak dokuları üzerine mum ile $1 \mathrm{~mm}$. rölyef yapılır. Ayrıca kanin ve 1.büyük azı bölgesinde stop oluşturulur. 
- $\quad$ Bu model üzerine soğuk akrilikten ya da işıkla sertleşen akrilikten bireysel ölçü kaşığı hazırlanır.

- Ölçü başlıkları, ağız içerisinde implantlar üzerine vidalanır.

- Hasta ağzında implant analoglarının denk geldiği yerlere, vida kısmı kaşığın dışına çıkacak şekilde kaşık üzerinde frezle delikler hazırlanır. Kaşığın ağız içine uyumu kontrol edilir ve uygun ölçü materyali ile ölçü alınır.

- Ölçünün sertleştiğinden emin olduktan sonra, ölçü başlıklarının vidaları gevşetilerek, kaşık ile birlikte ölçü başlıkları da hasta ağzından uzaklaştırılır.

Avantajlart,

- Hastaya özel kaşık hazırlığı ile birlikte, ölçü maddesine yer açılarak, ölçü maddesinin her yerde eşit dağılım göstermesi ve istenilen kalınlıkta şekillendirilebilmesi sağlanır. Böylece daha doğru bir ölçü elde edilir.

- Kaşı içerisinde hazırlanan stoplar yardımıyla, ölçü alımı esnasında kaşığın dokuya gömülmesinin ve ölçü maddesinin kalın şekillenmesinin önlenebilmesi ve kaşığın stabilizasyonu elde edilir.

- Direkt teknik implantların açılanması nedeniyle ölçü materyalinde oluşabilecek deformasyon riskini azaltmaktadır.

- İndirekt tekniğin aksine, ölçü içine tekrar yerleştirilmesine gerek kalmaması, yerleştirmeye bağlı oluşabilecek hataları elimine etmektedir.

Dezavantajlarl,

- Hekim için daha komplike olan ve hassasiyet gerektiren bu teknik klinik uygulanımı zor bir metottur.

- Splintleme yapılmadı ise, ölçü başlıklarının ağızdan çıkartılmadan önce gevşetilmesi esnasında rotasyonu söz konusu olabilir.

- Ölçü başlıkları için hazırlanan deliklerin kalın çapta olması, ölçü alımı sırasında basıncı düşürerek, ölçü materyalinin yumuşak doku üzerinde ve implantlar çevresinde yayılmasını olumsuz yönde etkileyecektir.

- Ölçü başlığ1 ve implant analoglarının bağlanması sırasında rotasyonel bir hareket oluşturma olasıllı̆ı gibi dezavantajları mevcuttur.
Ölçünün doğruluk derecesinin arttırılması ve ölçüde distorsiyonun azaltılması için, çok üyeli implantların ölçü alımında hem direkt hem de indirekt teknikler öncesinde implantların stabilitelerinin sağlanması için splintleme yapılması tavsiye edilmektedir. Özellikle direkt teknikte ölçü başlıklarının, ölçü ağızdan çıkarılırken veya implant analoğuna sabitlenirken hareket etmesi en çok gözlenen problemlerden birisidir (Conrad ve ark, 2007, Lee ve ark., 2008, Kempler, 2011). Splintleme için kullanılan materyaller arasında akrilik rezin, otopolimerizan akrilik rezin, 1şıkla sertleşen kompozit rezin ve ölçü alçısı vardır (Lee ve Cho, 2011). Splintleme tekniğinde en çok karşılaşılan sorunlar splint materyalinin distorsiyonu ve splint materyali ve ölçü başlığı arasındaki bağlantının kopmasıdır.

Günümüzde ölçü materyallerinin gelişmesiyle boyutsal stabilite ve rijidite artmış; ölçüyü ağızdan çıkarırken deformasyona uğramaları azalmıştır. $\mathrm{Bu}$ sayede özel vakalar dışında splintleme işlemine gerek duyulmamaktadır (Del'Acqua ve ark., 2010).

İmplant destekli protetik diş tedavisinde, implant üstü ölçü prosedürleri, tedavinin iki değişik aşamasında uygulanmaktadır. Bunlar:

\section{Abutment seviyesinde:}

- İyileşme başlı̆̆ çıkarıldıktan sonra, abutment hasta ağzında implant üzerine yerleştirilir.

- Abutment hasta ağzında diş kesimi kuralları dahilinde prepare edilir.

- Prepare edilen abutment üzerinden diş destekli sabit protez hazırlığı için alınan konvansiyonel ölçü gibi ölçü alınır.

- Alınan ölçü, laboratuvara gönderilir ve abutment üstüne döküm yapılarak üst yapı elde edilir.

- $\mathrm{Bu}$ teknikle, ölçü aşaması basitleştirilmiş olur. Tek diş implant tedavilerinde, abutmentın diğer dişler ile olan ilişkisini hekim kendi isteğine göre hazırlayabilir. Ancak laboratuvar aşamalarında teknik hassasiyetin sağlanması için, abutment seviyesinde implant ölçüsü alınması pek tavsiye edilmemektedir (Buzayan ve ark, 2013).

\section{Implant seviyesinde:}

Direkt ölçü tekniği veya indirekt ölçü tekniği kullanılabilir. Metodun aşamaları direkt ve indirekt ölçü tekniklerindeki gibidir. Ölçü başlığı olarak vidalı titanyum başlıklar veya plastik başlıklar kullanılabilir. Tek üyeli 
implant ölçülerinin alımında da implant seviyesinde ölçü tavsiye edilmektedir (Buzayan ve ark, 2013).

Araştırmacılar, implant seviyesinde protetik tedavi için alınan kaydın, abutment seviyesinde alınan kayda göre bazı avantajlarını savunmaktadırlar. Bu avantajları,

- Geçici restorasyon yapımında kolaylık sağlanması,

- Laboratuvarda doğru abutmentın seçilmesi,

- Hastaya özel veya ajuste edilen abutmentların hazırlanabilmesi olarak sıralanabilir.

\section{2. Üç Boyutlu Dijital Ölçü Tekniği}

Dijital tarayıcıların gelişimi diş hekimliği alanında uygulama sahasını da genişletmiştir. Diş hekimliğinde yüzyılların pradigması olan ölçü tekniği sistemlerini de değiştiren bu yenilikçi teknoloji gelişimini hızla sürdürmektedir.

CAD-CAM sistem ile üretilen abutment çeşitleri, dijital ağız içi tarayıcıların kullanılmasına izin vermektedir. Dijital ölçü yöntemi, dijital olarak tasarlanmış bir protetik restorasyonun ilk basamağını oluşturmaktadır (Lee ve ark., 2013). Bu sistem ile ölçü alımı çok daha basitleştirilmiş, hastanın ünitte kalma süresi kısaltılmış, klinisyen ve diş teknisyeni arasında iletişim kolay hale getirilmiştir (Lin ve ark., 2013, Eliasson ve Ortorp, 2012). Dijital verilerle oluşturulan ölçünün, geleneksel elastomerik ölçü materyali ve teknikleriyle alınan ölçüye göre materyal distorsiyonu gibi olumsuz yönleri elimine etmesiyle, hasta ağzını daha doğru yansıttığ 1 ve CAD-CAM teknolojisiyle elde edilen üst yapının marjinal uyumun daha iyi olduğu bulunmuştur. Ayrıca osseointegrasyonun erken dönemlerinde dokulara temas olmadan ölçü alınması da önemli bir avantajıdır.

Dijital ölçü kullanımı sayesinde restore edilecek bölgedeki protetik boşluğun, ara yüz derinliğinin, vestibül ve mukogingival durumunun, abutment tasarımının ve çıkış profili konfigürasyonunun daha detaylı değerlendirilmesi üretilen restorasyonların uyumunu artırmaktadır (Patel, 2010). Dijital ölçü ile elde edilen taramalar ile CAD/CAM teknolojisi kombine edilerek implant destekli sabit ve tam protezler dijital iş akışı ile üretilebilmektedir (Lee ve ark., 2013).

Piyasada bulunan başlıca intraoral dijital tarayıcılar CEREC, Lava C.O.S., Cadent iTero, E4D ve TRIOS sistemidir.
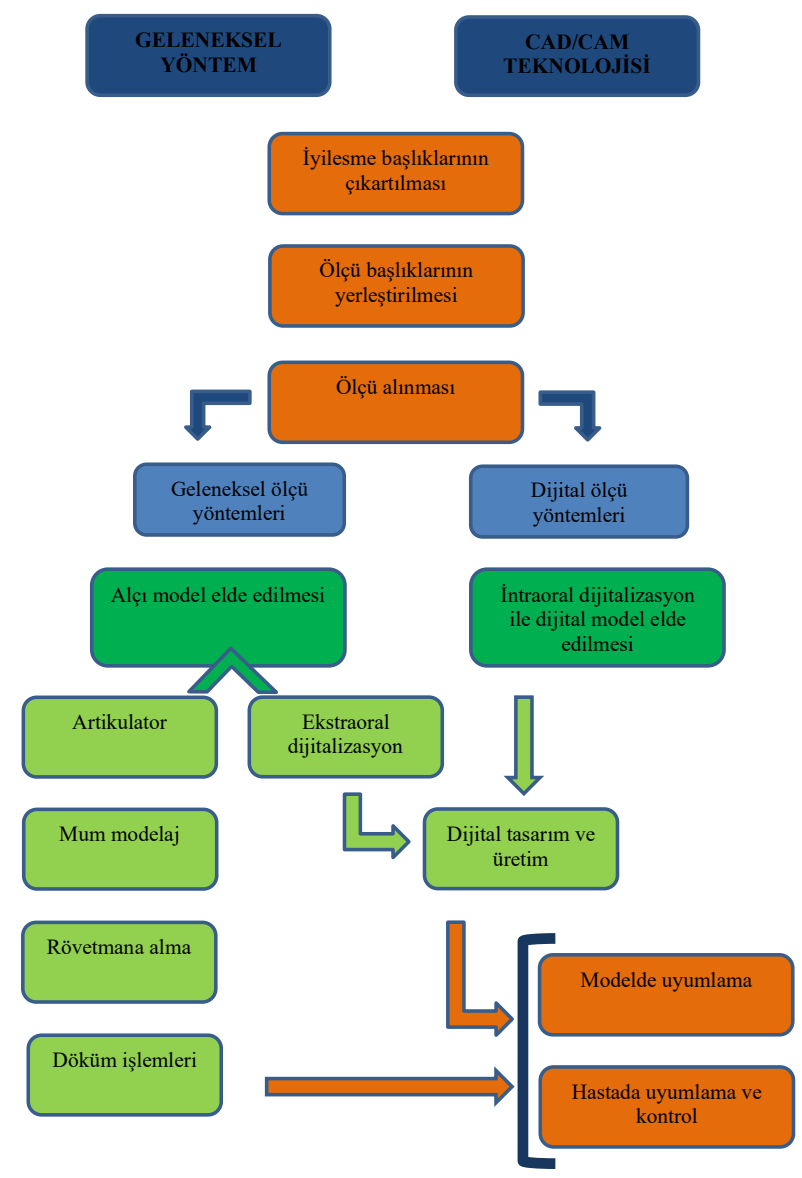

Implant destekli protetik restorasyonların ölçü teknikleri birbirleriyle karsılaștırıldı ğında;

İmplant destekli protetik restorasyonlarda sıklıkla kullanılan indirekt ve direkt ölçü yöntemlerinin hangisinin daha başarılı olduğu konusunda pek çok çalışma yapılmıştır ancak sonuçlar üzerinde tam bir fikir birliği sağlanamamaktadır. Direkt ölçü yönteminin indirekt tekniğe göre daha üstün olduğunu gösteren çalışmaların varlığına karşın (Lee ve Gallucci, 2013, Jo ve ark., 2010); indirekt ölçü yöntemi ile daha başarılı ölçü elde edildiğini öne süren araştırmalar da bulunmaktadır (De La Cruz ve ark., 2002). İndirekt tekniğin, özellikle ağız açıklığının kısıtlı olduğu ve hastada bulantı refleksi olup kaşı̆̆ın hemen çıkarılması gerektiği durumlarda daha fazla tercih edilebileceği önerilmektedir (De La Cruz ve ark., 2002). Diğer yandan, her iki ölçü yöntemi arasında ölçü doğruluğu açısından fark olmadığını savunan çalışmalar da bulunmaktadır (Daoudi ve ark., 2004).

Modellerdeki transfer deformasyonları azalan sıralamasıyla; direkt - splintlenmiş teknik >direkt splintlenmemiş teknik >indirekt teknik olarak karşımıza çıkmaktadır. 
Cabral ve ark'nın yaptıkları çalışmalarda splintlemenin altyapının pasif uyumu açısından daha iyi olduğunu belirtmiştir (Cabral ve Guedes, 2007). Naconecy ve ark, çelik pin ve akrilik rezin ile ölçü öncesi splintleme yapmış ve analog pozisyonunun doğruluğu açısından splintlemenin daha iyi olduğunu belirtmiştir (Naconecy ve ark., 2004). Aynı şekilde, diş ipi ve akrilik rezin ile splintlemenin yapıldığ 1 çalışmalarda splintlemenin ölçü doğruluğu ve altyapı deformasyonunun azlığı açısından daha iyi olduğu rapor edilmiştir (Faria ve ark., 2011). Diğer yandan, splintleme yapılmadan da pasif uyuma sahip restorasyonların elde edilebileceği görüşü de belirtilmiştir (De La Cruz ve ark., 2002). Ayrıca, akrilik rezin ile splintlenen ve splintlenmeyen ölçü teknikleri açısından fark olmadığını gösteren çalışmalar da bulunmaktadır (Choi ve ark., 2007).

Júlio CBF ve ark'nın yaptıkları çalışmada akrilik rezin ile splint yapılan direkt ölçü tekniği grubu, implant destekli protetik restorasyonların ölçü yöntemlerinde en güvenilir ve doğru sonucu veren teknik olarak bulunmuştur (Júlio ve ark., 2011).

Papaspyridakos ve ark, direkt splintli ve direkt splintsiz ölçü tekniklerinin protezin pasif uyumu üzerindeki etkisini değerlendirmişlerdir. Bu amaçla, 12 hastanın toplam 13 dişsiz arkına yerleştirilmiş 80 implant üzerinden ölçü alınmıştır. Direkt splintli ölçü tekniğinde ölçü kopinglerini splintlemek için akrilik rezin kullanılmış tüm yöntemlerde ise ölçü materyali olarak polieter kullanılmıştır. Elde edilen modeller üzerine $\mathrm{CAD} / \mathrm{CAM}$ sistemiyle zirkonya altyapılar hazırlanmıştır. Direkt splintli ölçü tekniğinin uygulandığg 13 arktan elde edilen modellerden 12 tanesinde klinik olarak pasif oturan bir protetik restorasyon elde edilirken, direkt splintsiz ölçü tekniğinin uygulandığı 13 arktan elde edilen modellerden ise sadece 6 tanesinde pasif oturan protetik restorasyon elde edilmiştir. Klinik araştırmanın sonucunda, tam dişsiz arklar üzerine implant destekli tek parça protez yapımında, direkt splintli ölçü tekniğinin splintsiz tekniğe oranla çok daha hassas ölçü verdiği tespit edilmiştir (Papaspyridakos ve ark., 2012).

Naconecy MM ve ark'a göre direkt - splintlenmiş teknik, çok üyeli abutment sistemleri için en uygun yöntemdir (Naconecy ve ark., 2004).

Lee SJve Gallucci GO, diş hekimliği 2.sınıföğrencileriyle yaptıkları çalışmada, fantom modeller üzerindeki 12 implant ile dijital ve konvansiyonel ölçü yöntemlerinin etkinliklerini karşılaştırmıştır. Dijital ölçü alımının daha etkin bir yöntem olduğu bildirilmiştir. Konvansiyonel ölçü alımına göre daha kısa hazırlık, çalışma ve yeniden alınma süreleri gerektirdiği tespit edilmiştir. Yapılan çalışmalarda dijital ölçü alımı klinik anlamda daha kolay olarak değerlendirilmiştir (Lee ve Gallucci, 2013).

Baskai KG'nin çalışmasında konvansiyonel ölçü tekniği ile elde edilen modeller ile dijital olarak oluşturulan modeller arasındaki doğruluk değerlendirilmiştir. Dijital ölçü tekniği ile elde edilen modellerin, konvansiyonel teknik ile elde edilenlere göre daha az güvenilir olduğu bulunmuştur ve klinik olarak kabul edilebilir ölçü modelleri elde edilememiştir (Baskai, 2014, Lee ve ark., 2015).

\section{3. ÖLÇÜ MATERYALLERİ}

Protetik bir apareyin fabrikasyonu için, protezin oturacağ 1 zeminin negatifini elde etmekte kullanılan materyallere ‘ölçü materyalleri' adı verilir (Çalıkkocaoğlu, 1998). Günümüze dek dental literatürde yer verildiği üzere, restore edilmesi gereken dokulara uygun protez yapımındaki hassasiyet, ölçü materyali tipine doğrudan bağlıdır. Bu materyallerin farklı fiziksel ve kimyasal özelliklere sahip çeşitli tipleri mevcuttur ve ölçü materyalleri araştırmacılar tarafından farklı şekillerde gruplandırılırlar, fakat genelde kullanılan sınıflandırma şu şekilde karşımıza çıkar:

\section{Reversible ölçü materyalleri}

2. İrreversible ölçü materyalleri

Son yıllarda artan boyutsal stabilite, rijidite ve ince detay yeteneği nedeniyle sabit ve hareketli protez ölçülerinde irreversible ölçü materyallerinden elastomerik (lastik) esaslı ölçü materyalleri ile ölçü alınması yaygınlaşmıştır. Sentetik lastik olarak da adlandırılan bu maddeler, dört tiptir (Kempler, 2011, Lee ve Cho, 2011).

- Polisülfit lastik esaslı materyaller

- Silikon lastik esaslı materyaller:

- Polivinilsiloksanlar ve Konvansiyonel silikonlar olmak üzere ikiye ayrılırlar.

- Polieter lastik esaslı materyaller

- Vinilsiloksaneter esasli materyaller (Aslan, 2012).

Yüksek boyutsal stabiliteleri, bekleme sırasındaki düşük büzülme yüzdeleri, yüksek rijidite ve ölçü başlıklarının ölçü içinde rotasyona uğramaması gibi avantajlarından dolayı implant destekli protetik restorasyonlarında tercih edilen ölçü materyallerinden detaylı olarak bahsedecek olursak (Aslan, 2012); 


\section{1. İlave Tip Silikon (Polivinilsiloksan) Ölçü Maddeleri}

İlave tip silikonlar, kondanzasyon silikonların özelliklerinin modifiye edilmesi ile ortaya çıkmıştır. Yapılan modifikasyon ile yan ürünlerin oluşmadığı bir reaksiyon sağlanmış ve böylece ölçü maddesinin sertleşmesinden sonra oluşabilecek boyutsal değişikliği elimine edilmiştir (Craig ve Powers, 2002, O’Brien 2002).

İlave silikonların herikipatı dabenzeriçerikte olduğundan genellikle aynı form ve kıvamdadır. Bu da baz ve katalizörün daha kolay karıştırılabilmelerini sağlamaktadır (Craig ve Powers, 2002). İlave silikonların oldukça fazla hidrofobik özellik göstermelerinden dolayı ortaya çıkan problemleri azaltmak daha az hidrofobik olmalarını sağlamak ve temas açısını azaltmak için bazı ürünlere surfaktanlar ilave edilmektedir (Rubel, 2007). İlave silikonların yapısına ilave edilen bir başka madde de paladyumdur. Paladyumun görevi ise aslında bir reaksiyon yan ürünü olmayan ama karıştırılan patlardaki prepolimerlerin eşit oranda olmamasıly ortaya çıkan hidrojeni bağlamaktır (Rubel, 2007).

Polivinilsiloksanlar için dikkat edilmesi gereken bir özellik, ölçü maddesi hazırlanırken lateks eldivenlerle temas edilmemesi hatta ölçünün alınacağı bölgeye bile lateks eldivenlerle dokunulmaması gerekliliğidir. Çünkü sülfürün polivinilsiloksan materyalinin polimerizasyonunu inhibe ettiği belirlenmiştir (Kimoto ve ark., 2005). Lateks eldivenin içindeki sülfürün ve retraksiyon ipinde bulunan sülfürün etkisi vardır.

Son araştırmalar polimerizasyonu inhibe ettiği düşünülen kanama durdurucu ajanlar ve retraksiyon solüsyonlarının böyle bir etkisinin olmadığını göstermiştir. Ölçüde dişeti sulkusu bölgesindeki düzensizlikler bu bölgelerin fazla nemli bırakılmasından kaynaklandığı bulunmuştur (Rupp ve ark., 2008).

İlave silikonlar boyutsal olarak oldukça stabildir. İlave tip silikonlardan birden fazla model elde etmek de mümkündür (Donovan ve Winston, 2004).

\subsection{Polieter Ölçü Maddeleri}

İki tüp içerisinde bulunur. Baz patın içinde bir prepolimer ve doldurucular vardır. Katalizör patında ise reaksiyon başlatıcılar, pat formu vermek için yağlar ve doldurucular bulunur.

Tek viskozitede bulunan polieter ölçü maddesi pseudoplastik özelliği dolayısıyla hem şırınga edilerek hem de direkt kaşığa yerleştirilerek kullanılabilir (O’Brien
2002, Endo ve Finger, 2006). Pseudoplastik davranış (kayma incelmesi) sayesinde üreticiler tek fazlı ölçüler üretebilmektedir. Bu özellik sayesinde hekim distorsiyona daha dirençli visköz materyaller kullanarak istenilen netlikteki ölçüyü alabilmektedir. Pseudoplastik davranış sadece kuvvet uygulandığında oluşur ve materyali kalıcı olarak deformasyona uğratmaz (Philips ve Anusavice, 2007).

Reaksiyon ilave tipte bir polimerizasyon olduğu için sonucunda herhangi bir yan ürün ortaya çıkmaz. $\mathrm{Bu}$ da maddenin boyutsal olarak oldukça stabil olmasını sağlar (Endo ve Finger, 2006). Polieterler elastomerlerin en çok sertleşeni olarak kabul edilirler. Bu yüzden fazla andırkatlı yüzeylerden çıkarılmaları oldukça güçtür. Bu özelliği, çok andırkatlı alanlarda kullanılmasını sınırlar (Holst ve ark, 2007).

Polieter ölçü maddeleri \%98,5 oranında elastik geri dönüşüm gösterirler. $\mathrm{Bu}$ değer polivinilsiloksanlar ile polisülfidler arasındadır. Polieter ölçü maddeleri polimerizasyonlarından 24 saat sonra gösterdikleri $\% 0,3$ 'lük büzülme ile boyutsal stabilite açısından ölçü maddeleri içinde en üst sıralarda, ilave tip silikonların hemen altında bulunmaktadırlar. Ancak polieter ölçü maddeleri hidrofilik yapıda oldukları için su emerler ve bu da boyutsal stabilitelerini bozar. Bu nedenle ölçü kuru ortamda saklanmalıdır. Kuru bir ortamda bekletilen bir polieter ölçü maddesi 1 haftaya kadar boyutsal stabilitesini koruyabilir (Craig ve Powers, 2002).

\subsection{Vinilsiloksaneter (Vinil Polieter Silikon (VPES)) Ölçü Maddeleri}

Üreticiler polieter ve polivinilsiloksan ölçü materyallerinin özelliklerini kombine etmek amacıyla yeni bir elastomerik ölçü maddesi geliştirmişlerdir. 2009 yılında piyasaya sürülmüştür. Polivinilsiloksaneter (PVSE) olarak da adlandırılan bu yeni materyalin iyi mekanik özellik, akıc1lık gösterdiği ve ıslanabilirliğinin ve doğruluğunun da mükemmele yakın olduğu iddia edilmektedir.

Üreticiler surfaktan eklemeye gerek olmadan hidrofilik özelliği arttırmak amaciyla \%5-20 oranında polieter eklenmiştir. Mekanik özellikleri PE ve PVS ile benzerdir (Nassar ve ark., 2013, Enkling ve ark., 2012, Pandita ve ark., 2013). Polieter ölçü maddesine göre kullanımının daha rahat olduğu bildirilmiştir. Yüksek yırtılma direnci sayesinde en sıkı yerlerden bile yırtılmadan çıkabileceği iddia edilmektedir. Akıcılığı sayesinde ölçü yüzeyinde 
kabarcık oluşmasını minimuma indirir ve tat olarak hastayı rahatsız etmez (Enkling ve ark., 2012). Kimyasal yapısında polisiloksan ve divinilpolieter vardır.

Polivinilsiloksaneter ölçü maddesinin polietere iyi bir alternatif olacağı belirtilmiştir (Enkling ve ark., 2012).

Implant destekli protetik restorasyonlar için tercih edilen bu 3 ölçü materyali karşılaş̦tırıldı̆ğnda;

Araştırmaların büyük bir çoğunluğunda polieter ve PVS ölçü materyalleri arasında bir fark bulunamazken (Lorenzoni ve ark., 2000, Wenz ve Hertrampf, 2008) baz1 araştırmalarda (Lee ve ark, 2008, Sorrentino ve ark., 2010, Buzayan ve ark., 2013). PVS'nın polietere kiyasla daha doğru ölçü verdiği, Del'Acqua ve ark tarafından yapılan araştırmada ise polieterin daha doğru sonuçlar verdiği öne sürülmüştür (Del'Acqua ve ark., 2010).

1. gün ve 1. haftada boyutsal stabilitelerine göre değerlendirilen materyaller, artan siralamasiyla; Polivinilsiloksan $<$ Polivinilsiloksaneter $<$ Polieter olarak değerlendirilmiştir (Aslan, 2012).

Paralel ve açılı abutmentların, polivinilsiloksan ve polieter ölçü materyali ile oluşturulan ölçülerinde benzer boyutsal veriler bulunmuştur. Her iki materyal ile de paralel ve açılı abutmentların ölçüsü alınabilir bulunmuştur (Akalin ve ark., 2013, Reddy ve ark., 2013).

Wee, farklı viskozitelere sahip polieter ve PVS ölçü materyalleri ile direkt ölçü tekniği kullanarak ölçü almıştır. Ölçü materyallerinin rijiditesini ve ölçü başlıklarını kavrama derecesini değerlendirmek amaciyla, her ölçü materyalinin içindeki ölçü başlığını rotasyona uğratmak için gerekli tork kuvvetleri ölçülmüştür. İmplant ölçüleri için, orta viskozitedeki polieter veya yüksek viskozitedeki PVS'ın kullanımını önermiştir.Farklı ölçü materyallerini distorsiyona uğratan ortalama tork değerleri değişiklik göstermiştir ve ortalama tork değerleri azalan sıralaması ile; Polieter $>$ polivinillsilikon $>$ polisülfid olarak bulunmuştur (Wee, 2000). Polieter ve vinilsiloksaneterin karşılaştırıldığ 1 klinik bir çalışmada (Enkling ve ark., 2012), 3-5 implant yerleştirilmiş hastalardan her iki ölçü maddesiyle de ölçü alınmış. Hastaların, klinisyenlerin ve teknisyenlerin ölçü maddelerini değerlendirmesi istenmiştir. Hastalar ölçü maddesini tat açısından; klinisyenler manipülasyon, çalışma zamanı, ölçünün detaylar konusundaki hassasiyeti ve kalitesi açısından; teknisyenler ise ölçü başlıklarını ölçü materyallerinin kavraması, rotasyon oluşturmaması ve alçı modelin elde edilmesi sırasında materyalin hidrofiliközelliği, modelin detay hassasiyeti açısından skorlamışlardır. Ayrıca iki farklı ölçü materyali ile elde edilen modeller üzerine kronlar fabrike edilmiş ve uyumları değerlendirilmiştir. Subjektif ve objektif değerlendirmeler sonucu VSE'in polietere denk veya üstün özellikler gösterdiği; implant ölçülerinde iyi bir alternatif olduğu belirtilmiştir (Enkling ve ark., 2012, Tokar ve ark., 2017).

Pandita ve ark, VSE ve PVS ile alınan ölçülerden farklı zaman aralıklarında tekrar tekrar model elde etmiş ve her iki materyalin de mükemmel boyutsal stabilite gösterdiğini, ölçü alındıktan 2 hafta sonra bile model elde edilebileceği belirtilmiştir (Pandita ve ark., 2013).

Nassar ve ark polieter, VSE ve PVS ölçü materyallerinin boyutsal stabilitesini farklı zaman aralıklarında elde edilen alçı modeller üzerinde değerlendirmiştir (Nassar ve ark., 2013). Ölçü alınır alınmaz elde edilen modeller kıyaslandığında, VSE ile en doğru model elde edilmiştir. Araştırmacılar test edilen 3 materyalin de boyutsal stabilitesinin çok iyi olduğunu; ancak, polieterden ölçü alındıktan sonra en geç 24 saat içinde, VSE ile de en geç 1 hafta içinde model elde edilmesi gerektiğini öne sürmüşlerdir.

\section{SONUÇ}

- İmplant üstü sabit ve hareketli protezlerin uyumu, modelin doğruluk derecesine direkt bağlıdır. Buda ölçü materyalini, implant ölçü tekniğini, kaşık tipini, splintleme yapılmasını önemli hale getirmiştir.

- İmplant ölçü teknikleri arasında çalışmaların kısıtlamaları dahilinde en güvenilir sonuç veren, doğruluk konusunda üstünlük sağlayan teknik, splintleme yapılmış direkt teknik/ açık kaşık tekniğidir.

- İmplantların birbirine paralel olduğu durumlarda veya implant sayısının 4'ten az olduğu durumlarda hem direkt hem de indirekt ölçü yöntemleri uygulanabilir.

- Çok sayıda implant varlığında, direkt ölçü tekniğinin kullanılması ve ölçü başlıklarının splintlenmesi önerilmektedir. İmplantlar arasındaki açı farkının fazla olduğu durumlarda da direkt teknik ve splintleme işleminin daha iyi sonuçlar verdiği gözlenmiştir. Ancak implant sayısının ve implantlar arasında açılanmanın $15^{\circ}$ den az olduğu durumlarda indirekt teknik de uygulanabilir.

- İndirekt ölçü tekniği en yüksek ortalama distorsiyon değeri sergilemiştir. 
- İmplant üstü restorasyonlarda boyutsal stabilitesi, deformasyona uğramaması ve rijit olmasından dolayı polieter ve polivinilsiloksan ölçü maddesinin kullanımı avantaj sağlamaktadır. Bu iki materyalin birbirlerine göre üstünlüklerini destekleyen araştırma sayısı sinırlidir.

- VSE ölçü materyali ile ilgili yeterli araştırma bulunmamakla birlikte mevcut araştırmalar incelendiğinde, polieter ve PVS ile karşılaştırılabilir derecede doğru ölçüler verdiği tespit edilmiştir.

\section{KAYNAKLAR}

1. Akalin ZF, Ozkan Y, Ekerim A. Efects of Implant Angulation, Impression Material, and Variation in Arch Curvature Width on Implant Transfer Model Accuracy. Int J Oral Maxillofac Implants. 2013; 28:149-157.

2. Aslan YU. Farklı ölçü maddelerinin boyutsal stabilite ve doğruluk, yüzey detayı, değme açısı ve sslanabilirlik açısından değerlendirilmesi. M.Ü. Sağlık Bilimleri Enstitüsü, Doktora Tezi, 2012, İstanbul (Danışman: Prof. Dr. Yasemin Kulak Özkan).

3. Baskai KG. Evaluation of Digital Implant Impressions using an Intra-oral Computerized Scanner (iTero) versus Conventional Implant Impressions: A 3-Dimensional Analysis of Accuracy. Science Faculty of Dentistry University, Thesis for the degree of Masters, 2014, Toronto. (Direct: Hasan ALKUMRU).

4. Branemark PI. Introduction to osseointegration, in Branemark PI, Zarb GA, Albrektsson T. eds. TissueIntegrated Prostheses. Chicago: Quintessence; 1985; 11-76.

5. Buzayan M, Baig MR, Yunus N. Evaluation of accuracy of completearch multiple-unit abutment-level dental implant impressions using different impression and splinting materials. Int J Oral Maxillofac Implants. 2013; 28:15121520.

6. Cabral LM, Guedes CG, Comparative analysis of 4 impression techniques for implants. Implant Dent. 2007; 16:187-94.

7. Carr AB. Comparison of impression techniques for a twoimplant 15-degree divergent model. Int J Oral Maxillofac Implants. 1992; 7: 468.

8. Choi JH, Lim YJ, Yim SH, Kim CW. Evaluation of the accuracy of implant-level impression techniques for internalconnection implant prostheses in paralel and divergent models. Int J Oral Maxillofac Implants. 2007; 22(5):761-8.

9. Conrad HJ, Pesun IJ, Delong R, Hodges JS. Accuracy of two impression techniques with angulated implants. J Prosthet Dent. 2007; 97:349-356.

10. Craig RG, Powers JM. Restorative Dental Materals, 11th Edition. Toronto: Mosby Co.: 2002; 53-65.

11. Çalıkkocaoğlu S. Tam Protezler. 3. Baskı. İstanbul: Quintessence: 1998; 147-160.
12. Daoudi MF, Setchell DJ, Searson LJ. An evaluation of three implant level impression techniques for single tooth implant. Eur J Prosthodont Restor Dent. 2004; 12:9 - 14.

13. De La Cruz JE, Funkenbusch PD, Ercoli C, Moss ME, Graser GN, Tallents RH. Verification jigs made of different materials. J Prosthet Dent. 2002; 88:329-36.

14. Del'Acqua MA, Chávez AM, Compagnoni MA, Molo Fde A Jr. Accuracy of impression techniques for an implantsupported prosthesis. Int J Oral Maxillofac Implants. 2010; 25:715-21.

15. Donovan TE, Winston C. A review of contemporary impression materials and techniques. Dent Clin N Am. 2004; 48:445-470.

16. Eliasson A, Ortorp A. The accuracy of an implant impression technique using digitally coded healing abutments. Clinical implant dentistry and related research. 2012; 14:30-8.

17. Endo T, Finger WJ. Dimensional accuracy of a new polyether impression material. Quintessence Int. 2006; 37(1):47-51.

18. Enkling N, Bayer S, Jöhren $\mathrm{P}$, Mericske-Stern R. Vinylsiloxanether: a new impression material. Clinical study of implant impressions with vinylsiloxanether versus polyether materials. Clin Implant Dent Relat Res. 2012; 14:144-151.

19. Faria JC, Silva-Concílio LR, Neves AC, Miranda ME, Teixeira ML. Evaluation of the accuracy of different transfer impression techniques for multiple implants. Braz Oral Res. 2011; 25:163-7.

20. Holst S, Blatz MB, Bergler M, Goellner M, Wichmann M. Influence of impression material and time on the 3 dimensional accuracy of implant impressions. Quint Int. 2007; 38:67-73.

21. Jo SH, Kim KI, Seo JM, Song KY, Park JM, Ahn SG Ahn. Effect of impression coping and implant angulation on the accuracy of implant impressions:an in vitro study. J Adv Prosthodont. 2010; 2:128-33.

22. Júlio CBF, Laís RSC, Ana CCN, Milton EM, Marcelo LT. Evaluation of the accuracy of different transfer impression techniques for multiple implants. Braz Oral Res. 2011; 25:82.

23. Kahramanoğlu E, Kulak-Özkan Y. The effect of different restorative and abutment materials on marginal and internal adaptation of three-unit cantilever implantsupported fixed partial dentures: an in vitro study. J Prosthodont. 2013;22(8):608-17.

24. Kempler J. The Effect of Impression Technique, Connection Type and Implant Angulation on Impression Accuracy. Faculty of Graduate School of the University of Maryland, Master Thesis, 2011, Maryland (Direct: Assistant Professor Dr. Radi Masri).

25. Kimoto K, Tanaka K, Toyoda M, Ochiai KT. Indirect latex glove contamination and its inhibitory effect on vinyl polysiloxane polymerization. J Prosthet Dent. 2005; 93:4338.

26. Lee H, Ercoli C, Funkenbusch PD, Feng C. Effect of subgingival depth of implant placement on the dimensional accuracy of the implant impression: an in vitro study. J Prosthet Dent. 2008; 99:107-113. 
27. Lee H, So S, Hochstedler JL, Ercoli C. The accuracy of implant impressions: a systematic review. J Prosthet Dent. 2008; 100:285-291.

28. Lee SJ, Betensky RA, Gianneschi GE, Gallucci GO. Accuracy of digital versus conventional implant impressions. Clin Oral Implants Res. 2015; 26(6):715-9.

29. Lee SJ, Cho SB. Accuracy of five implant impression technique: effect of splinting materials and methods. J Adv Prosthodont. 2011; 3:177-185.

30. Lee SJ, Gallucci GO. Digital vs. conventional implant impressions: efficiency outcomes. Clin Oral Implants Res. 2013; 24:111-115.

31. Lee SJ, Macarthur RX 4th, Gallucci GO. An evaluation of student and clinician perception of digital and conventional implant impressions. J Prosthet Dent. 2013; 110:420-423.

32. Lin WS, Harris BT, Morton D. The use of a scannable impression coping and digital impression technique to fabricate a customized anatomic abutment and zirconia restoration in the esthetic zone. J Prosthet Dent. 2013; 109:187-191.

33. Lorenzoni M, Pertl C, Penkner K, Polansky R, Sedaj B, Wegscheider WA. Comparison of the transfer precision of three different impression materials in combination with transfer caps for the Frialit-2 system. J Oral Rehabil. 2000; 27:629-638.

34. Misch CE. Presents the rationale for implant treatment with interesting statistics and demographic trends. In: Dental Implant Prosthetics, Morton LP, 0-323-01955-2, Mosby Co,: 2005; 13-15.

35. Naconecy MM, Teixeira ER, Shinkai RS, Frasca LC, Cervieri A. Evaluation of the accuracy of 3 transfer techniques for implant-supported prostheses with multiple abutments. Int $\mathrm{J}$ Oral Maxillofac Implants. 2004; 19:192-8.

36. Naert I, Quirynen M, Theuniers G, Van Steenberghe D. Prosthetic aspects of osseointegrated fixtures supporting overdentures. A 4-year report. J Prosthet Dent. 1991; 65:67180 .

37. Nassar U, Oko A, Adeeb S, El-Rich M, Flores-Mir C. An in vitro study on the dimensional stability of a vinyl polyether silicone impression material over a prolonged storage period. J Prosthet Dent. 2013; 109:172-178.

38. O'Brien WJ. Dental Materials and Their Selection. Chicago: Quintessence Publishing Co, 2002; 145-168.
39. Pandita A, Jain T, Yadav NS, Feroz SM, Pradeep, Diwedi A. Evaluation and comparison of dimensional accuracym of newly introduced elastomeric impression material using 3D laser scanners: an in vitro study. J Contemp Dent Pract. 2013; 14:265-268.

40. Papaspyridakos P, Benic GI, Hogsett VL, White GS, Lal K, Gallucci GO. Accuracy of implant casts generated with splinted and non-splinted impression techniques for edentulous patients: an optical scanning study. Clin Oral Implants Res. 2012; 23:676-681.

41. Patel N. Integrating three - dimensional digital technologies for comprehensive implant dentistry. J Am Dent Assoc 2010; 141:20-24.

42. Philips RW, Anusavice KJ. Philips Science of Dental Materials, 11th Ed. Philedelphia: Saunders Co.: 2007; 93102.

43. Reddy S, Prasad K, Vakil H, Jain A, Chowdhary R. Accuracy of impressions with different impression materials in angulated implants. Nigerian Journal of Clinical Practice. 2013; (16)3: 279-284.

44. Rubel B, Impression materials: A comparative review of impression materials most commonly used in restorative dentistry. Dent Clin N Am. 2007; 51:629 - 642.

45. Rupp F, Axmann D, Geis-Gerstorfer J. Effect of relative humidity on the hydrophilicity of unset elastomeric impression materials. Int J Prosthodont. 2008; 21(1) 69-71.

46. Sorrentino R, Gherlone EF, Calesini G, Zarone F. Effect of implant angulation, connection length, and impression material on the dimensional accuracy of implant impressions: an in vitro comparative study. Clin Implant Dent Relat Res. 2010; 12:63-76.

47. Şahin S, Çehreli MC, Yalçin E. The influence of functional forces on the biomechanics of implant supported prostheses-a review. J Dent. 2002; 30:271-82.

48. Tokar E, Polat S, Uludağ B. Evaluation of effect of impression techniques to satisfaction of edentulous patients treated with implant-retained overdentures: a pilot study. 2017;27(2):100106.

49. Wee AG. Comparision of impression materials for direct multi-implant impressions. J Prosthet Dent. 2000; 83:323-31.

50. Wenz HJ, Hertrampf K. Accuracy of impressions and casts using different implant impression techniques in a multiimplant system with an internal hex connection. Int J Oral Maxillofac Implants. 2008; 23:39-47. 